\title{
IMPORTÂNCIA DO CORPO PARA A FAMÍLIA ENLUTADA: CRENÇAS, RITUAIS E SENTIMENTOS QUE PODEM INTERFERIR NA DOAÇÃO DE ÓRGÃOS
}

\author{
Importance of the body for the bereaved family: beliefs, rituals and feelings that \\ might interfere in the organ donation
}

\author{
Daniela Barros
}

\section{RESUMO}

A morte é um fenômeno que invariavelmente está presente no cotidiano de todas as famílias. Apenas os seres humanos, dentre todos os seres vivos, sabem que morrerão. A família exerce papel mediador no processo saúdedoença, como mantenedora da saúde, e na doença participando do processo de cura, reabilitação e morte. Portanto, acontecimentos de ordem natural e acidental com um dos membros afetam o corpo familiar, e a possibilidade de ruptura de um vínculo pela morte causa intensa desestruturação emocional, psicológica e espiritual. Assim como o casamento, a morte também é um ato ritualizado. O próprio funeral funciona como um rito de passagem, que ajuda a família a internalizar e aceitar o óbito. Os enlutados iniciam os ritos de separação do morto, onde permanecem até se sentirem prontos para a suspensão do luto e reintegração social. Os velórios, funerais e outros rituais relacionados com a morte servem para contextualizar a experiência. A devoção nos cuidados com o cadáver revela a inquietação que a morte provoca e a tentativa dos enlutados em buscar por conforto e aceitação. Nesse contexto, analisamos como a relação com o corpo do parente falecido, considerando-se todos os rituais fúnebres e o luto em si, pode interferir na decisão da família em doar ou não os órgãos. A literatura evidencia que, dentre as famílias entrevistadas, $15,7 \%$ do total recusaram a doação, sendo que $17,6 \%$ destas enfatizaram o desejo de manter o corpo íntegro. Outra razão apontada pelos familiares na recusa à doação foi o tempo para a devolução do corpo, para começar os cortejos fúnebres, que é cerca de 24 horas. A recusa familiar para a doação de órgãos é permeada por questões legais, morais, éticas e religiosas. Por mais necessário que seja o aumento das autorizações para a doação de órgãos, possibilitando a continuidade de vidas desconhecidas, há que se respeitar a decisão de cada família, tomada no contexto de seu repertório.

Descritores: Família; Luto; Doação de Órgãos; Rituais Fúnebres; Corpo Humano.

Instituição:

Programa de Medicina (Clínica Cirúrgica) da Faculdade de Medicina de Ribeirão Preto, Universidade de São Paulo (FMRPUSP). Departamento de Cirurgia e Anatomia - São Paulo/SP

\section{Correspondência:}

Daniela Barros

Rua Mariana dos Reis Patricio, 90 / 71 - CEP 14022-103 - Ribeirão Preto/SP

+5515 99713-0806

danielabarros@usp.br

Recebido em: 14/09/2020

Aceito em: $\quad 18 / 12 / 2020$

\section{INTRODUÇÃO}

"A família de hoje não é mais nem menos perfeita do que aquela de ontem: ela é outra, porque as circunstâncias são outras"

\section{Émile Durkheim ${ }^{1}$}

A família é, sem dúvida, a instituição humana mais antiga. Todo indivíduo nasce em razão da família e acaba associando-se com seus demais membros em menor ou maior intensidade e intimidade. ${ }^{2}$ 
No entanto, o conceito do que vem a ser família é extremamente volátil e mutante, pois acompanha a evolução dos ideais sociais, das descobertas científicas e dos costumes da sociedade, sendo impossível de se construir uma ideia sólida e fixa do seu significado e das suas características. ${ }^{2}$

Segundo Bordieu, "a família é um conjunto de indivíduos aparentados, ligados entre si por aliança, casamento, filiação, ou, excepcionalmente por adoção (parentesco), vivendo sob um mesmo teto (coabitação)". ${ }^{3}$

Antigamente, o modelo familiar predominante era 0 patriarcal, patrimonial e matrimonial, em que havia a figura do "chefe de família", representando o centro do núcleo familiar e responsável pela tomada das decisões. Era tido como o provedor e suas decisões deveriam ser seguidas por todos. ${ }^{2}$ Bordieu explica que "a família que somos levados a considerar como natural, porque se apresenta com a aparência de ter sido sempre assim, é uma invenção recente e, quem sabe, voltada à desaparição mais ou menos rápida (como levam a crer o aumento da taxa de coabitação fora do casamento e as novas formas de laços familiares inventados a cada dia)". ${ }^{3}$

Nesse mesmo artigo, intitulado "O espírito de família", o autor discorre sobre o universo paralelo formado por esse grupo, chegando a considerá-lo como sagrado e secreto, em que a soleira da porta representa uma barreira simbólica delimitando o espaço restrito apenas a seus membros. ${ }^{3}$

A mulher desempenha um papel fundamental na criação de laços na família, seja por meio das atividades da vida cotidiana, visitas aos parentes, telefonemas e organização de festas e encontros: "Esse trabalho de integração é tanto mais indispensável, porque a família, que para existir e subsistir deve afirmar-se como corpo, sempre tende a funcionar como um campo, com suas relações de força física, econômica e, sobretudo, simbólica". ${ }^{3}$

Outro papel atribuído à família é o da reprodução, não apenas biológica, mas também social. Isso implica em diversas simbologias, como a transmissão do sobrenome aos herdeiros, do patrimônio e a preservação da memória e cultura dos antepassados e no compartilhamento de interesses (tanto econômicos como outros em comum àqueles que habitam a mesma unidade doméstica). ${ }^{3}$

\section{Vivência do processo de morte na família}

Agora que revisamos o conceito de família e suas principais configurações, partimos para um fenômeno que, invariavelmente, está presente no cotidiano de todas elas: a morte. "Embora compartilhem o nascimento, a doença, a juventude, a maturidade, a velhice e a morte com os animais, apenas os seres humanos, dentre todos os seres vivos, sabem que morrerão". ${ }^{4}$

Antigamente, nas sociedades primitivas, o momento da morte acontecia de maneira pública. Desse modo, as pessoas lidavam coletivamente com suas angústias. A perda e o luto quase sempre eram vividos e compartilhados por todos, incluindo-se as crianças e os vizinhos. Cada cultura possuía seus rituais, que antecediam os momentos finais da pessoa até o ato de preparar o corpo e velá-lo. Esse modelo de gestão familiar do morrer foi denominado morte tradicional. ${ }^{4}$

A partir da década de 1960, com o progresso do intensivismo médico, a morte foi transferida da casa para o hospital, passando do domínio familiar para o domínio dos técnicos de saúde, como em um processo de "terceirização". Com isso, os familiares passaram de agentes a espectadores da morte de seus entes queridos. ${ }^{4}$

Conforme explicam Borges e Mendes, essa mudança trouxe consequências para o âmago familiar, pois, sendo a família o núcleo básico social, é nele que se fundamentam e fomentam as relações de afeto, intimidade e consanguinidade que formam os laços entre seus membros. Como uma unidade interacional, a família é afetada por cada um dos membros, que, por sua vez, influenciam uns aos outros. Desse modo, ela exerce papel mediador no processo saúde-doença, mantendo a saúde, e na doença participando do processo de cura, reabilitação e morte. Logo, acontecimentos de ordem natural e acidental com um dos membros afeta o corpo familiar, e a possibilidade de ruptura de um vínculo pela morte causa intensa desestruturação emocional, psicológica e espiritual. ${ }^{4}$

\section{Rituais de luto e a simbologia do corpo para a família}

Assim como o casamento, a morte também é um ato ritualizado. O próprio funeral funciona como um rito de passagem que ajuda a família a internalizar e a aceitar o óbito.

Em cada lugar do mundo e nas diferentes culturas existem formas de se lidar com o processo da morte e com os rituais que se seguem, sejam eles de cunho social ou religioso. O mais comumente observado é que o corpo seja preparado por um agente funerário, velado em local específico, e posteriormente, enterrado no cemitério ou cremado. O jazigo em que o corpo fica enterrado ou as cinzas espalhadas têm forte valor simbólico para os entes queridos, que, muitas vezes, fazem "visitas" e homenagens, inclusive no dia de finados.

No entanto, algumas culturas possuem cerimônias bem peculiares. Em diversos países da África, o funeral 
corresponde a um casamento, onde centenas de parentes, amigos e conhecidos participam das tradições funerárias que são seguidas de um banquete. Algumas cerimônias podem durar até uma semana. Acredita-se que se o falecido não ficar satisfeito com seu funeral, poderá voltar para assombrar os vivos. ${ }^{5}$

Já no Himalaia, os mortos são esquartejados e oferecidos aos abutres. Chamados de "rituais dos céus", as partes são levadas a um lugar ermo e comidos pelas aves, evitando, portanto, a disseminação de doenças. ${ }^{6}$

Mais recentemente, por conta da pandemia causada pelo novo coronavírus, as pessoas ao redor do globo precisaram ressignificar seus ritos fúnebres, já que velórios com caixões abertos são estritamente proibidos pela alta possibilidade de transmissão do vírus.

No Brasil, temos acompanhado o drama dos índios Yanomamis. Algumas moradoras da aldeia Auaris, localizada em Roraima, fronteira do Brasil com a Venezuela, foram levadas junto a seus bebês para Boa Vista, com suspeitas de pneumonia. No hospital, as crianças teriam sido contaminadas por covid-19 e lá morreram. Seus corpos desapareceram, possivelmente enterrados em valas comuns no cemitério da cidade. A partir daí intensifica-se o drama dessas mães. Além de doentes, sem falar uma palavra em português, elas imploram pelos corpos de seus bebês. ${ }^{7}$

Se não bastasse a dor e o luto da morte de seus filhos, essas mães temem que, sem um funeral adequado, a alma deles padeça na erraticidade. O que o "homem branco" não compreende é que enterrar o corpo de um Yanomani é como arrancá-lo do mundo dos humanos, um ato extremamente violento, incompreensível e inaceitável para eles. ${ }^{7}$

Os Yanomami em nenhuma hipótese são enterrados. De acordo com Brum, os corpos são cremados e há um longo ritual para que o morto possa morrer para si e para a comunidade.

"Os Yanomami não são indivíduos, como um branco que vive no Brasil ou na Espanha ou nos Estados Unidos. Um Yanomami compreende-se como parte de uma comunidade e entrelaça-se com várias dimensões de mundos visíveis e invisíveis em relações mediadas pelos xamãs". ${ }^{7}$

Os rituais de morte devem ser seguidos em todos os detalhes e levam meses e até anos para serem concluídos. Eles incluem a visita de índios de várias aldeias vizinhas para participar da cremação. As cinzas são guardadas, e meses depois, quando os visitantes retornam para as celebrações, são diluídas em mingau de banana para que aquele que morreu se dissipe no corpo de todos. ${ }^{7}$

\section{A importância de vivenciar o luto}

Segundo o dicionário Aurélio, da língua portuguesa, "luto" significa tanto o sentimento de dor pela morte de alguém, quanto os sinais exteriores desse sentimento, em especial o traje usado (como roupas pretas) e o tempo de permanência em estado de luto. É considerada reação normal e esperada frente ao rompimento de uma relação significativa, pois compreende-se que ocorre não simplesmente uma morte, mas a partida de alguém amado em circunstância dolorosa. ${ }^{8}$ Portanto, tal processo constitui-se como uma experiência subjetiva, ou seja, dotada de significado, inserida em uma cultura e multideterminada. ${ }^{9}$

Já o ato de ritualizar significa marcar um aspecto da realidade ou um acontecimento. Os enlutados iniciam os ritos de separação do morto onde permanecem até sentirem-se prontos para a suspensão do luto e reintegração social. ${ }^{8}$

Os velórios, funerais e outros rituais relacionados com a morte servem para contextualizar a experiência. Portanto, a universalidade das manifestações humanas diante da morte existe para atender às necessidades psicológica e social de dar um enquadramento e uma previsibilidade à perda pela morte. ${ }^{8}$

O autor Imber-Black descreve as funções dos rituais de luto como necessárias para "marcar a perda de um dos membros da família; afirmar a vida como foi vivida pelo que morreu; facilitar a expressão do luto conforme os valores da cultura; falar sobre a morte e sobre a vida que continua expressando significados; apontar uma direção que faça sentido diante da perda e da continuação da vida dos que ficaram". Além do mais, o investimento e dedicação presentes nos rituais poderão ajudar o indivíduo a confrontar-se com a perda concreta, entrando no processo de luto, possibilitando-Ihe também a manifestação pública de seu pesar. ${ }^{8}$

\section{Doação de órgãos: uma abdicação do corpo?}

A devoção nos cuidados com o cadáver e os rituais fúnebres que se seguem revelam a inquietação que a morte provoca e a tentativa dos enlutados em buscar por conforto e aceitação. Independentemente da religião ou cultura, fica clara a importância que os rituais e o corpo desempenham para as famílias no processo do luto. Nesse sentido, prosseguimos com a presente reflexão em outra esfera relacionada à morte: a doação de órgãos.

Compreendida por uma parcela da população como continuidade da vida, a doação ainda é um tabu para muitos, que preferem nem discutir o assunto; afinal, doar órgãos na maioria das vezes implica na morte de alguém. 
Acolher a família de um potencial doador numa hora de tamanha dor e fazer com que ela compreenda que a pessoa que apresenta batimento cardíaco, movimentos respiratórios e temperatura corporal preservada está morta, do ponto de vista médico (morte encefálica), é muito difícil. ${ }^{10}$ Nos casos de falecimentos abruptos, como por acidentes, é uma situação ainda mais delicada, já que não existia um histórico de doença que pudesse preparar paulatinamente para tal desfecho.

As pesquisadoras Dalben e Caregnato buscaram conhecer os impeditivos das famílias para a doação. Os resultados evidenciaram que, dentre as famílias entrevistadas, $15,7 \%$ do total recusaram a doação, sendo que $17,6 \%$ destas enfatizaram o desejo de manter o corpo íntegro. ${ }^{11}$ Assim como elas, diversos outros autores também atestaram esse mesmo motivo, como Moraes e Massarollo ${ }^{12}$ e Pessoa e cols. ${ }^{13}$

Outra razão apontada pelos familiares na recusa à doação foi o tempo para a devolução do corpo para começar os cortejos fúnebres, que é cerca de 24 horas (período esse necessário para que todos os procedimentos da retirada dos órgãos e posterior liberação do corpo sejam concluídos). ${ }^{13}$ Esse dado reforça a urgência da família em passar pelos ritos fúnebres e vivenciar seu luto, como se a ausência do corpo não permitisse esse início.

\section{Doação de órgãos no Brasil}

Em números absolutos, o Brasil é o segundo país do mundo em número de transplantes. ${ }^{14} \mathrm{O}$ último boletim de 2019 do Registro Brasileiro de Transplantes indicou que este foi um ano difícil, em que a recuperação da taxa de doadores e de transplantes ocorreu apenas no último trimestre, associada a vários fatores. Um deles foi a ampla divulgação na mídia nacional sobre a doação de órgãos e tecidos do apresentador Gugu Liberato. Após ser constatada a morte encefálica, sua família atendeu ao desejo que ele expressou em vida e permitiu a doação dos órgãos. ${ }^{15}$

Além dos familiares que não permitem a doação, cabe ressaltar que uma parte considerável dos profissionais de saúde também não compreende ou não aceita o diagnóstico de morte encefálica. Existem, ainda, casos de pessoas que rechaçavam a doação por desacreditar no Sistema Único de Saúde (SUS), chegando a cogitar a hipótese de que poderiam ter o tratamento adiado para que seus órgãos fossem retirados.14 Tais crenças são descabidas, considerando-se a seriedade das entidades envolvidas no processo de captação e doação de órgãos. Há que se separar as lendas urbanas sobre roubo e venda de órgãos e atentar-se ao comprometimento e esforço de todos os envolvidos nessa luta em prol da vida.
Quando se fala em doação de órgãos, é natural que se pense nos atos de amor e altruísmo. Na verdade, é preciso refletir sobre os benefícios de forma global. Aquele que concede a doação de um órgão, hoje, pode beneficiar-se desse ato no futuro caso necessite de um transplante, também. Além disso, são muitos os benefícios da doação à família da pessoa falecida. Familiares entrevistados, meses após o óbito do doador, revelam que a doação funciona como um instrumento de consolo. Para alguns, ela é uma forma de gerar algo significativo de uma situação tão sem sentido, como a morte. Para outros, ela propicia um prolongamento da vida em outro corpo. Para um terceiro grupo, representa um ato de boa vontade que ajuda a aproximação entre o ente querido e Deus. A doação torna-se, portanto, uma oportunidade para a família intervir favoravelmente nos destinos espirituais do parente morto. ${ }^{16}$

Cada país possui regras próprias sobre a doação de órgãos e tecidos. Em alguns, a pessoa pode registrar em vida seu desejo, que deve ser respeitado e não poderá ser refutado por familiares. Por exemplo, na Holanda, o senado aprovou uma lei determinando que todos os holandeses saudáveis, acima de 18 anos, são considerados automaticamente doadores de órgãos, exceto se expressarem por escrito que não têm a intenção de sê-lo. ${ }^{17}$

No Brasil, não existe nenhum mecanismo legal para garantir a vontade de ser ou não doador. Somente a família pode autorizar a doação e decidir se acata ou não a vontade do falecido, quando comunicada em vida. Conforme estabelece o artigo $4^{\circ}$ da lei 9.434/97, "a retirada de tecidos, órgãos e partes do corpo de pessoas falecidas para transplantes ou outra finalidade terapêutica dependerá da autorização do cônjuge ou parente, maior de idade, obedecida a linha sucessória, reta ou colateral, até o segundo grau inclusive, firmada em documento subscrito por duas testemunhas presentes à verificação da morte". ${ }^{18}$

\section{CONSIDERAÇÕES FINAIS}

Compreender o significado dos laços familiares, da importância dos ritos fúnebres e do corpo físico para a família é de fundamental importância no processo da doação de órgãos. Segundo Rachel Sztajn, professora da Faculdade de Direito da Universidade de São Paulo (USP), "tanto no Direito quanto na Bioética, existe uma enorme consideração à autonomia do indivíduo. Mas, morto não tem vontade. E de quem é o corpo? O corpo é da família e a lei respeita a autonomia dos familiares". ${ }^{18}$

Considerando-se toda a análise sobre o corpo para a família, podemos inferir que um dos obstáculos à 
doação de órgãos é a maneira como ela poderia romper com a integridade corporal do falecido, já que alguns entendem $\mathrm{o}$ ato como uma mutilação. Outro aspecto diz respeito às simbologias. Um exemplo é o coração, notadamente conhecido, não apenas pela bomba máster do organismo, mas como o abrigo do amor e dos sentimentos. Abrir mão dele poderia representar um rompimento com o ente querido. ${ }^{19}$

A recusa familiar para a doação de órgãos é permeada por questões legais, morais, éticas e religiosas. Apenas a pessoa responsável pela decisão sabe de suas crenças e sentimentos, somados a todo estresse e tristeza presentes no contexto da morte. Por mais necessário que seja o aumento das autorizações para doação de órgãos, possibilitando a continuidade de vidas desconhecidas, há que se respeitar a decisão de cada família, tomada no contexto de seu repertório. No entanto, os profissionais de saúde e os formadores de opinião (como jornalistas e influenciadores, por exemplo), têm por missão educar a população sobre o tema, desfazer mitos e sanar dúvidas para aumentar a conscientização e, consequentemente, o número de doações.

\section{ABSTRACT}

Introduction: Death is a phenomenon that is invariably present in the daily lives of all families. Only human beings, of all living beings, know that they will die. The family plays a mediating role in the health-disease process as a health maintainer and, in the disease, participating in the healing, rehabilitation and death process. Therefore, the events of a natural and accidental order with one of the members affected by the family body and the possibility of breaking a bond due to death causes intense emotional, psychological and spiritual disruption. Like marriage, death is also a ritualized act. The funeral itself functions as a rite of passage that helps the family to internalize and accept death. The mourners begin the rites of separation from the dead where they remain until they feel ready for the suspension of mourning and social reintegration. The funerals and other rituals related to death serve to contextualize the experience. Devotion to care for the corpse reveals the anxiety that death causes and the attempt of the mourners to seek comfort and acceptance. In this context, we analyze how the relationship with the body of the deceased relative, considering all the funeral rituals and the mourning itself, can interfere in the family's decision to donate the organs or not. The literature shows that, among the families interviewed, $15.7 \%$ of the total refused to donate, and $17.6 \%$ of these emphasized the desire to keep the body intact. Another reason cited by family members in refusing to donate was the time it takes to return the body to start the funeral processions, which is about 24 hours. The family refusal to donate organs is permeated by legal, moral, ethical and religious issues. However, although we need to increase the authorizations for organ donation and, thus, allowing the continuation of unknown lives, it is necessary to respect the decision of each family, taken in the context of their repertoire.

Keywords:Family; Bereavement; Organ Donation; Funeral Rites; Human Body.

\section{AGRADECIMENTO}

Agradeço ao meu orientador, Professor Dr. Orlando de Castro e Silva, pelo incentivo e apoio irrestritos, ao Professor Dr. Geraldo Romanelli, que me auxiliou na reflexão sobre esse importante tema que faz parte do cotidiano de todas as famílias e ao

Professor Dr. Antonio Ruffino, que me inspira por meio de suas poesias. 


\section{REFERÊNCIAS}

1. Araujo MF. Paradoxos da família contemporânea. Psicologia \& Sociedade. 2011;23(2):436-437.

2. JusBrasil. A evolução da ideia e do conceito de família. Disponível em: https://advocaciatpa.jusbrasil.com.br/ artigos/176611879/a-evolucao-da-ideia-e-do-conceitode-familia. Acesso em: jun. de 2020.

3. Bordieu P. O espírito de família. In: Razões práticas sobre a teoria da ação. Campinas, Papirus Editora, 1996;124-35.

4. Borges MS, Mendes N. Vivências perante a morte: representações sociais de familiars de pacientes for a de possibilidades de cura. Rev. Min. Enferm. 2012;16(2):217-24.

5. Pessarolo J, Ferraro M. Funerais na África têm valor de casamentos. Pandemia os esvaziou. Disponível em: https://gauchazh.clicrbs.com.br/mundo/noticia/2020/05/ funerais-na-africa-tem-valor-de-casamentospandemia-os-esvaziou-ckaaxiiep00mf01mj7qey6opy. html. Acesso em: jun. de 2020.

6. BBC News. Mortos são esquartejados e oferecidos a abutres em funerais no Himalaia. Disponível em: https://www.bbc.com/portuguese/ noticias/2011/02/110211_funeral_urubus_himalaias_rw. Acesso em: jun. de 2020.

7. El País. Mães Yanomami imploram pelos corpos de seus bebês. Disponível em: https://brasil.elpais.com/ brasil/2020-06-24/maes-yanomami-imploram-peloscorpos-de-seus-bebes.html. Acesso em: jun. de 2020.

8. Souza CP, Souza AM. Rituais Fúnebres no Processo do Luto: Significados e Funções. Psicologia: Teoria e Pesquisa. 2019;35:e35412.

9. Braz MS, Franco MHP. Profissionais Paliativistas e suas Contribuições na Prevenção de Luto Complicado. Psicologia: Ciência e Profissão. 2017;37(1):90-105.
10. Graf CP, Castro e Silva O. Doação de órgãos e transplante: um binômio a ser otimizado. Medicina (Ribeirão Preto, Online). 2017;50(5):345-8.

11. Dalbem GG, Caregnato RCA. Doação de órgãos e tecidos para transplante: recusa das famílias. Texto contexto - enferm. 2010;19(4):728-35.

12. Moraes EL, Massarollo MCKB. Recusa de doação de órgãos e tecidos para transplante relatados por familiares de potenciais doadores. Acta paul. enferm. 2009;22(2):131-5.

13. Pessoa JLE, Schirmer J, Aguiar RB. Avaliação das causas de recusa familiar a doação de órgãos e tecidos. Acta paul. enferm. 2013;26(4):323-30.

14. Registro Brasileiro de Transplantes. Dimensionamento dos Transplantes no Brasil e em cada estado (20112018). Ano XXIV N 4: 2018.

15. Registro Brasileiro de Transplantes. Dimensionamento dos Transplantes no Brasil e em cada estado. Disponível em: http://www.abto.org.br/abtov03/Upload/file/ RBT/2019/RBT-2019-leitura.pdf. Acesso em: jun. de 2020.

16. Singh R, Agarwal TM, Al-Thani H, Maslamani Y, ElMenyar A. Validation of a Survey Questionnaire on Organ Donation: An Arabic World Scenario. Journal of Transplantation. Volume 2018, Article ID 9309486.

17. Coelho GHF, Bonella AE. Doação de órgãos e tecidos humanos: a transplantação na Espanha e no Brasil. Rev. Bioét. 2019;27(3):419-29.

18. Bonatelli C. Falecido não decide nada. Disponível em: http://www.usp.br/espacoaberto/arquivo/2007/ espaco80jun/0capac.htm. Acesso em: jun. de 2020.

19. Bendassolli PF. Doação de órgãos: meu corpo, minha sociedade. Psicologia: Reflexão e Crítica. 1998;11(1):7192. 